
Pathophysiology of Haemostasis and Thrombosis

Received: April 11, 2002

Accepted in revised form: May 20, 2002

\title{
Effect of an Ionic Compared to a Non-Ionic $X$-Ray Contrast Agent on Platelets and Coagulation during Diagnostic Cardiac Catheterisation
}

\author{
F. J ung ${ }^{a, b}$ S.G. Spitzera G. Pindurb \\ aDresdner Institut für Herz- und Kreislaufforschung, Dresden, bA bteilung für Klinische Hämostaseologie und \\ Transfusionsmedizin, Universität des Saarlandes, Homburg/Saar, Germany
}

\section{Key Words}

Ionic · Non-ionic · Radiographic contrast agent · Platelet function · Haemostasis · Ex vivo study · Coronary angiography

\begin{abstract}
The aim of the present study was to evaluate the effects of ionic (ioxaglate) and non-ionic (iopromide) contrast media on haemostatic parameters ex vivo. In 40 patients undergoing coronary angiography, platelet function (platelet reactivity and serotonin concentration) and coagulation markers [thrombin-antithrombin III complexes, prothrombin fragments $(F 1+2)$ and the D-dimers] were measured. The use of an ionic X-ray contrast agent (XCA) (ioxaglate) in diagnostic cardiac catheterisation angiography is associated with lower thrombin generation and lower activation of the platelet system than when a non-ionic XCA is employed (iopromide). The results thus confirm the results of various in vitro studies and animal investigations.
\end{abstract}

Copyright $\odot 2002$ S. Karger AG, Basel

\section{Introduction}

Various X-ray contrast agents (XCAs) are available in interventional cardiology. There are basically four different classes of contrast agents: ionic monomers, ionic dimers, non-ionic monomers and non-ionic dimers. They differ fundamentally in their physicochemical characteristics [for a review, see ref. 1]. These concern the iodine concentration, the osmolality, molecular structure, hydroand lipophilia, the electrical charge and solubility, the viscosity and the stability. These factors are responsible for the various biological and resulting clinical effects. Nonionic XCAs are used today in many cardiac catheterisation laboratories because of the somewhat better side effect profile. There have been a few randomised and nonrandomised investigations which showed that use of the ionic XCA ioxaglate was associated with a reduction in thrombotic events compared to the use of non-ionic XCAs [2-7]. This is in contrast to a study by Schräder et al. [8], in which an ionic XCA was not found to have any advantages.

It would be reasonable from the pathophysiological aspect to expect that ionic XCAs could have an advantage with regard to thrombotic events. After the first evidence in this direction when Robertson [9] observed that clots formed in syringes that were filled with a mixture of blood

\begin{tabular}{ll}
\hline KARGER & ( ) 2002 S. Karger AG, Basel \\
Fax +4161306 1234 $34-8832 / 02 / 0323-0121 \$ 18.50 / 0$ \\
$\begin{array}{l}\text { E-Mail karger@karger.ch } \\
\text { www.karger.com }\end{array}$ & $\begin{array}{l}\text { Accessible online at: } \\
\text { www.karger.com/journals/pht }\end{array}$
\end{tabular}

Prof. Dr. F. Jung

Dresdner Institut für Herz- und Kreislaufforschung

Forststrasse 5, D-01099 Dresden (Germany)

Tel. +493518064190, Fax +493518064199

E-Maildihkf@saarmail.de 
and non-ionic contrast agent, it was Chronos et al. [10] who showed in vitro that non-ionic contrast agents lead to platelet degranulation, which was not induced by ionic contrast agents. A recently published study, likewise in vitro, was able to show that ioxaglate markedly reduced thrombin generation and in particular markedly increased the effect of abciximab, a glycoprotein IIb/IIIa antagonist [11].

Results obtained in vitro are not always comparable to conditions as they occur in the endothelium-lined vascular system. We therefore investigated the effects of an ionic contrast agent (ioxaglate) compared to those of a non-ionic contrast agent (iopromide) on platelet function and plasma coagulation ex vivo.

\section{Patients and Methods}

\section{Study Design}

The study was a prospective randomised comparative study similar to that of Arora et al. [12]. There were two groups, each with 20 patients who underwent diagnostic cardiac catheterisation in which either an ionic or non-ionic XCA was employed. Two patients in the ioxaglate group and 3 patients in the iopromide group received 2,500 IU of heparin during the cardiac catheterisation angiography. No other medication was given.

Patients with raised creatinine levels who were having bypass angiography or additional imaging of the internal mammary artery were excluded. Diagnostic cardiac catheterisation was selected in order to ensure that activation by the procedure itself was as low as possible. The extent of the endothelial injury was monitored by measuring tissue factor, which is normally not detectable and is released only when there is damage to the vessel wall.

A blood sample was drawn and analysed before and 30 min after the end of the procedure. The parameters of primary haemostasis were circulating platelet aggregates and also the platelet count, and the serotonin concentration was used to measure platelet activation. The activation of the haemostasis system was detected by measuring parameters that rise significantly, particularly when thromboembolic processes are taking place. The following were measured to detect thrombin generation: thrombin-antithrombin III complexes, prothrombin fragments $(\mathrm{F} 1+2)$ and the D-dimers (split products of FXIII cross-linked fibrin strands induced by the action of plasma which indicate that coagulation has taken place with consequent fibrinolysis). Furthermore, endothelial injury factors such as tissue factor and thrombomodulin were measured, which possibly provide evidence of the degree of injury due to the catheter intervention.

\section{$X$-Ray Contrast Agents}

The ionic XCA used in this study was ioxaglate, trade name Hexabrix $320^{\circledR}$. Hexabrix 320 is an ionic hypo-osmolar XCA with a dimeric molecular structure. Its osmolarity is $600 \mathrm{mosm} / \mathrm{kg} \mathrm{H}_{2} \mathrm{O}$ and the $\mathrm{pH}$ is between 6.5 and 7.5 . The viscosity is $7.5 \mathrm{mPa}$ at $37^{\circ} \mathrm{C}$.

The non-ionic XCA used in this study was iopromide, trade name Ultravist $300^{\circledR}$. Ultravist 300 is a non-ionic XCA with a monomeric molecular structure. Its osmolarity is $770 \mathrm{mosm} / \mathrm{kg} \mathrm{H}_{2} \mathrm{O}$ and the $\mathrm{pH}$ is between 6.5 and 7.5. The viscosity is $9.5 \mathrm{mPa}$ at $37^{\circ} \mathrm{C}$.

\section{Measurement Methods}

Blood was drawn from a large-lumen cubital vein before each cardiac catheterisation procedure. Disposable syringes and a butterfly system with a needle diameter of $1.1 \mathrm{~mm}$ were employed. The blood was aspirated slowly and was mixed during aspiration by rotating the syringe. The syringes were prefilled for anticoagulation with isotonic $3.1 \%$ sodium citrate solution ( $1 \mathrm{ml}$ sodium citrate $/ 9 \mathrm{ml}$ blood).

Circulating platelet aggregates were detected as a parameter of primary haemostasis according to the $\mathrm{Wu}$ and Hoak [13] method with the modification of Grotemeyer [14]. The test set-up is founded on the basis that the platelet aggregates that exist in vivo or arise through blood collection are dissolved through the action of ethylenediamine tetra-acetic acid disodium (EDTA) and fixed immediately through EDTA plus formalin. The measurement results for both samples can be expressed as a quotient. If one places the value from the EDTA plus formalin sample in the denominator, then the quotient increases with the number of aggregates. The index for the platelet reactivity (PRI) is calculated as follows:

$$
\mathrm{PRI}=\frac{\text { platelets }(\text { EDTA }) \times \mathrm{RBC}(\text { EDTA }+ \text { formalin })}{\text { platelets }(\text { EDTA }+ \text { formalin }) \times \mathrm{RBC}(\text { EDTA })}
$$

The existing increased in vivo presence of thrombocyte aggregates has proven to be a reliable indicator of increased platelet function in cardiac infarction, cerebral infarctions or transitory ischaemic attacks [13]. A PR $>1.04$ is suspicious, and values greater than 1.2 are certainly pathological [14].

The serotonin concentration was measured as an indicator of platelet activation [15]. It was measured by means of ELISA (Coulter Immunotech, Hamburg, Germany). Activation of the haemostasis system was detected through parameters which rise significantly particularly when thromboembolic processes are taking place [16]. The following were measured to detect thrombin generation: thrombinantithrombin III complex, prothrombin fragments $(\mathrm{F} 1+2)$ and the D-dimers (split products of FXIII cross-linked fibrin strands induced by the action of plasma which indicate that coagulation has taken place with consequent fibrinolysis). The thrombin-antithrombin III complex was measured using the Enzygnost TAT ELISA (Behringwerke, Marburg, Germany) in the Quantum II photometer (Abbott, North Chicago, Ill., USA) [17]. The D-dimers were measured by ELISA using the EIA APP microreagent (Behringwerke) [17], and the prothrombin fragment F1+2 using the Enzygnost TAT ELISA (Behringwerke). The calibration was performed according to the standards for ELISA kits. The cut-off levels under the given experimental conditions were $0.5 \mu \mathrm{g} / \mathrm{ml}$ for the D-dimers and $3.2 \mathrm{ng} / \mathrm{ml}$ for the thrombin-antithrombin III complex.

Furthermore, tissue factor and thrombomodulin were measured as endothelial injury factors, which possibly provide evidence of the degree of injury at the site of ablation. Thrombomodulin was measured by ELISA using polyclonal antibodies to human thrombomodulin (Diagnostika, Stago, Asnieres Cedex, France) [18]. Tissue factor was measured by ELISA (American Diagnostics, Greenwich, USA).

\section{Statistics}

The statistical analysis was carried out in accordance with the European Community - Good Clinical Practice (EC-GCP) Note for Guidance. A sample size estimate was not possible since there were no data available.

In order to guarantee the integrity of the data, the case report forms were submitted in duplicate and then subsequently checked 
Table 1. Platelet parameters for both contrast agents before and $30 \mathrm{~min}$ after diagnostic cardiac catheter angiography

\begin{tabular}{|c|c|c|c|c|c|}
\hline & & Before & 30 min after & $\mathrm{p}_{\mathrm{b}-\mathrm{a}}$ & $\mathrm{p}_{\mathrm{G}}$ \\
\hline \multirow[t]{2}{*}{$\mathrm{PC}, 1,000 / \mu \mathrm{l}$} & $\mathrm{H}$ & $210.8 \pm 41.1$ & $191.1 \pm 39.7$ & 0.0001 & \multirow[t]{2}{*}{0.3033} \\
\hline & $\mathrm{U}$ & $232.5 \pm 64.1$ & $215.4 \pm 63.2$ & 0.0063 & \\
\hline \multirow[t]{2}{*}{ PRI, - } & $\mathrm{H}$ & $1.14 \pm 0.15$ & $1.08 \pm 0.23$ & 0.0383 & \multirow[t]{2}{*}{0.1926} \\
\hline & $\mathrm{U}$ & $1.13 \pm 0.09$ & $1.17 \pm 0.26$ & 0.5212 & \\
\hline \multirow[t]{2}{*}{ Serotonin, $\mathrm{n} M$} & $\mathrm{H}$ & $7.12 \pm 6.07$ & $7.28 \pm 6.35$ & 0.8822 & \multirow[t]{2}{*}{0.0333} \\
\hline & $\mathrm{U}$ & $6.78 \pm 5.01$ & $11.28 \pm 9.86$ & 0.0147 & \\
\hline
\end{tabular}

$\mathrm{p}_{\mathrm{b}-\mathrm{a}}=$ Comparison before versus after contrast agent; $\mathrm{p}_{\mathrm{G}}=$ comparison of the difference (baseline value minus value after the end of the procedure) between the contrast agents); $\mathrm{PC}=$ platelet count; PRI = platelet reactivity index; $\mathrm{H}=$ Hexabrix $^{\circledR} ; \mathrm{U}=$ Ultravist $^{\circledR}$. and compared. Any discrepancies were corrected on the basis of the original data. All random samples were expressed as the mean value and standard deviation. An explorative analysis established whether the parameters tested changed after the respective procedure compared to the initial value $\left(\mathrm{p}_{\mathrm{b}-\mathrm{a}}\right)$. The $t$ test for paired random samples was employed for the two-sided analysis. The null hypothesis is as follows: there is no difference between the initial value $\left(\mu_{\text {before }}\right)$ and the final value $\left(\mu_{\text {after }}\right)$, i.e. $\mu_{\text {before }}=\mu_{\text {after }}$. A difference was assumed for $\mathrm{p}_{\mathrm{b}-\mathrm{a}}<0.05$

Beyond this, it was also investigated whether each contrast medium had an influence on the parameters studied. For this, the differences between the initial value for the respective parameter and the value obtained $30 \mathrm{~min}$ after completing the procedure were calculated. These differences $\left(\mu_{\text {diff }} \mathrm{XCA} 1\right.$ and $\left.\mu_{\text {diff }} \mathrm{XCA} 2\right)$ were compared for the two contrast media $\left(\mathrm{p}_{\mathrm{G}}\right)$. Here, the null hypothesis is as follows: the two calculated differences do not differ from each other, i.e. $\mu_{\text {diff }} \mathrm{XCA} 1=\mu_{\text {diff } X C A 2}$. The $t$ test for unpaired random samples was employed for the two-sided analysis. A difference was assumed for $\mathrm{p}_{\mathrm{G}}<0.05$.

\section{Patients}

Eighteen patients in the ioxaglate group were male and 2 were female. The average age of the patients in this group was $63.1 \pm 6.3$ years, the average weight was $82.7 \pm 10 \mathrm{~kg}$ and the average height was $173 \pm 9 \mathrm{~cm}$. Nineteen patients in the iopromide group were male and 1 was female. The average age of the patients in this group was $60.8 \pm 10$ years, the average weight was $80.4 \pm 18 \mathrm{~kg}$ and the average height was $173.4 \pm 8 \mathrm{~cm}$. There were no demographic differences between the two groups.

Two patients in the ioxaglate group and 3 patients in the iopromide group had no coronary heart disease; 3 and 5 patients, respectively, had single-vessel disease; 6 and 5 patients, respectively, had twovessel disease; and 9 patients in the ioxaglate group and 7 patients in the iopromide group had triple-vessel disease. Fourteen patients in the ioxaglate group and 13 patients in the iopromide group were treated with acetylsalicylic acid.

The volume of contrast agent given was $141.3 \pm 35.1 \mathrm{ml}$ in the ioxaglate group and $142.0 \pm 35.1 \mathrm{ml}$ in the iopromide group. The two groups of patients did not differ with regard to the volume of contrast agent given $(p>0.05)$.

X-Ray Contrast Media and Haemostasis

\section{Results}

\section{Platelet System}

There was a marked fall in the number of individually circulating platelets after the use of both contrast agents $\left(\mathrm{p}_{\mathrm{b}-\mathrm{a}}=0.0001\right.$ and 0.0063 , respectively). The difference (platelet count before minus platelet count after cardiac catheter angiography) did not differ for the two contrast agents $\left(\mathrm{p}_{\mathrm{G}}=0.3033\right)$.

After giving ioxaglate, the platelet reactivity fell markedly $\left(\mathrm{p}_{\mathrm{b}-\mathrm{a}}=0.0383\right)$, while it was unchanged after iopromide $\left(p_{b-a}=0.5212\right)$. There was no difference between the two XCAs with respect to the differences (platelet reactivity before minus platelet reactivity after cardiac catheter angiography) $\left(\mathrm{p}_{\mathrm{G}}=0.1926\right)$.

The serotonin concentration did not change after ioxaglate $\left(\mathrm{p}_{\mathrm{b}-\mathrm{a}}=0.8822\right)$, while it rose markedly after iopromide $\left(p_{b-a}=0.0147\right)$. When the differences were compared, there was a significant difference between the two contrast agents $\left(\mathrm{p}_{\mathrm{G}}=0.0333\right)$. These results are summarised in table 1.

\section{Plasma Coagulation}

After injecting ioxaglate, the prothrombin fragments did not change $\left(\mathrm{p}_{\mathrm{b}-\mathrm{a}}=0.2575\right)$, while they rose after iopromide was used $\left(\mathrm{p}_{\mathrm{b}-\mathrm{a}}=0.0183\right)$. When the groups were compared (prothrombin fragments before minus prothrombin fragments after cardiac catheter angiography), there was a trend to a difference between them $\left(\mathrm{p}_{\mathrm{G}}=\right.$ 0.0882).

The D-dimers did not change after either ioxaglate or iopromide ( $\mathrm{p}_{\mathrm{b}-\mathrm{a}}=0.1816$ and 0.1682 , respectively). The difference (D-dimers before minus D-dimers after cardiac catheter angiography) did not differ for the two XCAs $\left(\mathrm{p}_{\mathrm{G}}=0.2238\right)$.

Pathophysiol Haemost Thromb 2002;32:121-126 
Table 2. Coagulation markers for both $\mathrm{XCAs}$ before and $30 \mathrm{~min}$ after diagnostic cardiac catheter angiography

\begin{tabular}{lllcll}
\hline & & Before & 30 min after & $\mathrm{p}_{\mathrm{b}-\mathrm{a}}$ & $\mathrm{p}_{\mathrm{G}}$ \\
\hline $\mathrm{F} 1+2,1,000 / \mu \mathrm{l}$ & $\mathrm{H}$ & $0.92 \pm 0.34$ & $1.02 \pm 0.39$ & 0.2575 & 0.0882 \\
& $\mathrm{U}$ & $0.91 \pm 0.24$ & $1.40 \pm 0.84$ & 0.0183 & \\
D-dimers, $\mu \mathrm{g} / \mathrm{ml}$ & $\mathrm{H}$ & $28.1 \pm 25.3$ & $24.6 \pm 22.7$ & 0.1816 & 0.2238 \\
& $\mathrm{U}$ & $40.7 \pm 45.9$ & $74.3 \pm 133.1$ & 0.1682 & \\
TAT, ng/ml & $\mathrm{H}$ & $12.6 \pm 12.9$ & $16.01 \pm 23.9$ & 0.3461 & 0.0288 \\
& $\mathrm{U}$ & $10.3 \pm 8.6$ & $31.52 \pm 34.4$ & 0.0034 & \\
\hline
\end{tabular}

$\mathrm{p}_{\mathrm{b}-\mathrm{a}}=$ Comparison before versus after contrast agent; $\mathrm{p}_{\mathrm{G}}=$ comparison of the difference (baseline value minus value after the end of the procedure) between the contrast agents); TAT $=$ thrombin-antithrombin III complex; $\mathrm{H}=$ Hexabrix $^{\circledR} ; \mathrm{U}=$ Ultravist $^{\circledR}$.
Table 3. Endothelial injury markers for both XCAs before and $30 \mathrm{~min}$ after diagnostic cardiac catheter angiography

\begin{tabular}{llcccc}
\hline & & Before & 30 min after & $\mathrm{p}_{\mathrm{b}-\mathrm{a}}$ & $\mathrm{p}_{\mathrm{G}}$ \\
\hline $\mathrm{TF}, \mathrm{pg} / \mathrm{ml}$ & $\mathrm{H}$ & $11.1 \pm 15.5$ & $9.6 \pm 12.7$ & 0.1293 & 0.6346 \\
& $\mathrm{U}$ & $11.8 \pm 11.0$ & $9.5 \pm 8.5$ & 0.0560 & \\
$\mathrm{TM}, \mathrm{ng} / \mathrm{ml}$ & $\mathrm{H}$ & $40.9 \pm 35.6$ & $35.6 \pm 34.9$ & 0.5896 & 0.9676 \\
& $\mathrm{U}$ & $45.4 \pm 54.7$ & $43.6 \pm 42.1$ & 0.9192 & \\
\hline
\end{tabular}

$\mathrm{p}_{\mathrm{b}-\mathrm{a}}=$ Comparison before versus after contrast agent; $\mathrm{p}_{\mathrm{G}}=$ comparison of the difference (baseline value minus value after the end of the procedure) between the contrast agents; $\mathrm{TF}=$

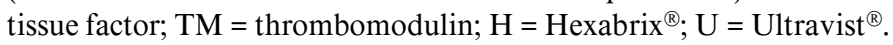

The thrombin-antithrombin III complexes did not change after ioxaglate $\left(\mathrm{p}_{\mathrm{b}-\mathrm{a}}=0.3461\right)$, while they rose markedly after iopromide $\left(\mathrm{p}_{\mathrm{b}-\mathrm{a}}=0.0034\right)$. The difference (thrombin-antithrombin III complexes before minus thrombin-antithrombin III complexes after cardiac catheter angiography) differed markedly for the two XCAs $\left(p_{G}=0.0288\right)$. These results are summarised in table 2 .

\section{Endothelial Injury Markers}

Thrombomodulin and tissue factor did not change after the diagnostic cardiac catheter angiography. There was no difference between the two contrast agents (table 3).

None of the patients had a major complication [19] during the course of the study, and there was no clinical evidence of nephrotoxicity (none of the patients initially had a creatinine value greater than $1.2 \mathrm{mg} / \mathrm{dl}$ ).

\section{Discussion}

None of the measured parameters (demographical, clinical, procedural and chemical) differed significantly between the two patient groups before the application of the contrast medium, so that comparability of the patient groups can be assumed.

Under the influence of activated factor $\mathrm{X}$ on prothrombin, thrombin and the prothrombin fragments $F 1+2$ are produced [20]. The resulting thrombin forms with antithrombin III an equimolar thrombin-antithrombin III complex, and this is considerably hastened by heparin [21]. In the present study, the markedly greater rise in prothrombin fragments $\mathrm{F} 1+2(\mathrm{p}=0.0882)$ and in the thrombin-antithrombin III complexes $(p=0.0288)$ when the groups were compared thus showed increased thrombin production after use of the non-ionic compared to the ionic XCA. Since the concentration of the endothelial injury markers thrombomodulin and tissue factor did not differ, the difference in thrombin production might be attributable to the XCA itself and not to different endothelial injuries. 
No medication was employed during the angiography (except that 2 patients in the ioxaglate group and 3 patients in the iopromide group received 2,500 IU of heparin). Our results show that the reduced thrombin release found by Chronos et al. [10] and recently by Al Dieri et al. [11] in vitro after ioxaglate compared to non-ionic XCAs is also found ex vivo. The increased thrombin release after the non-ionic XCA led to greater platelet activation, which is identifiable from the markedly increased serotonin release $(p=0.0033)$. Serotonin is released when platelets are activated and is regarded as a sensitive measurement to detect platelet stimuli $[22,23]$.

Platelet reactivity itself fell after ioxaglate, while it rose slightly after iopromide. These results confirm the investigations of Heptinstall et al. [24], who showed that ioxaglate inhibited ADP-induced platelet aggregation, while other non-ionic XCAs had pro-aggregatory effects and caused massive platelet degranulation. With regard to early platelet thrombus formation, there is no difference between ionic and non-ionic XCAs [25].

Although both XCAs are of low osmolality, their osmolality is still considerably higher than that of plasma. After injection of XCA, a shift of interstitial fluid into the vascular compartment rapidly compensates for this osmotic effect $[26,27]$. As a result of this compensation, the plasma volume increases by approximately $5-7 \%$. There was no difference in the effect on platelet count (and haematocrit) between the two XCAs, so that the haemodilution effect of the two XCAs was comparable.

Besides these in vitro studies, similar results have been obtained in several studies using animal models. Levi et al. [28] found that ionic XCAs had an inhibitory effect on thrombus formation and thrombus growth, while nonionic XCAs supported the formation of thrombosis. Aguejouf et al. [29] (found increased thromboembolic complications with non-ionic XCAs) and Corot et al. [30] (showed a significant reduction in thrombus formation with ionic XCA) found similar results.

One of the most serious complications associated with the use of XCAs arises from the interaction of the XCA with the coagulation system, the blood cells and the vessel wall, which can lead to partial or even complete vessel occlusion. This is promoted by the fact that many patients with coronary heart disease have an imbalance of the coagulation system, designated by Meade [31] as a prethrombotic condition. Patients with unstable angina have a particularly high risk, for instance when a plaque ruptures. As the principal mediator of thrombogenesis, thrombin plays a central role in the formation of vascular lesions [32, 33]. Moreover, thrombin is also a potent growth factor which initiates the proliferation of smooth muscle cells at vessel wall injuries and modulates the effects of other growth factors such as platelet-derived growth factor [34]. More recent clinical studies have confirmed that the findings described above have clinical implications. It has been shown angioscopically that significantly fewer intracoronary thrombi occur in patients with unstable angina during an intervention if ioxaglate is used as the XCA [6]. This may also explain the results published recently by Scheller et al. [35] concerning a reduced rate of acute and subacute stent stenosis.

As we did not collect blood samples after cardiac catheterisation but before giving XCA, we cannot estimate the influence of possible endothelial injuries or of the foreign surfaces of the port and catheter. A trend toward a transient influence on haemostatical parameters before giving XCA was shown by Biancardi et al. [36] and Hoffmann et al. [37], so that a procedural influence on haemostasis cannot be ruled out. Since the concentration of the endothelial injury markers thrombomodulin and tissue factor did not differ, the difference in thrombin production might be mainly attributable to the XCA itself and not to different endothelial injuries. A possible contact activation by the foreign surfaces of the port or catheters would have to be similar, since identical materials were used for both groups.

Blood samples were collected from a peripheral vein and not from the coronary sinus and, therefore, we may have overlooked local effects of XCA on haemostasis.

\section{Conclusions}

The use of an ionic XCA (ioxaglate) in diagnostic cardiac catheterisation angiography was associated with lower thrombin generation and lower activation of the platelet system than when a non-ionic XCA was employed (iopromide). The results of this ex vivo study thus confirm the data of various in vitro studies and animal investigations. 


\section{References}

1 Eloy R, Corot C, Belleville J: Contrast media for angiography: Physicochemical properties, pharmacokinetics and biocompatibility. Clin Mater 1991;7:891-897.

2 Piessens JH, Stammen F, Vrolix MC, Glazier JJ, Benit E, De Geest H, Willems JL: Effects of an ionic versus a nonionic low osmolar contrast agent on the thrombotic complications of coronary angioplasty. Cathet Cardiovasc Diagn 1993;28:99-105.

3 Gasperetti CM, Feldman MD, Burwell LR, Angello DA, Haugh KH, Owen RM, Powers ER: Influence of contrast media on thrombus formation during coronary angioplasty. J Am Coll Cardiol 1991;18:443-450.

4 Batchelor WB, Granger CB, Kleiman N, Phillips HR, Ellis SG, Betriu A, Criger DA, Stebbins AL, Topol EJ, Califf RM: A comparison of ionic versus nonionic contrast medium during primary percutaneous transluminal coronary angioplasty for acute myocardial infarction (GUSTO IIb). Global Use of Strategies to Open Occluded Coronary Arteries in Acute Coronary Syndromes. Am J Cardiol 2000;85:692-697.

5 Grines CL, Schreiber TL, Savas V, Jones DE, Zidar FJ, Gangadharan V, Brodsky M, Levin R, Safian R, Puchrowocz-Ochocki S, Castellani MD, O'Neill WW: A randomized trial of low osmolar ionic versus nonionic contrast media in patients with myocardial infarction or unstable angina undergoing percutaneous transluminal coronary angioplasty. J Am Coll Cardiol 1996;27:1381-1386.

6 Qureshi NR, den Heijer P, Crijns HJ: Percutaneous coronary angioscopic comparison of thrombus formation during percutaneous coronary angioplasty with ionic and nonionic low osmolality contrast media in unstable angina. Am J Cardiol 1997;80:700-704.

7 Lefevre T, Adjeroud N, Royer T, Glatt B, Morice $\mathrm{MC}$ : Influence of contrast media on the results of percutaneous transluminal coronary angioplasty with provisional stenting: A comparative study. J Invasive Cardiol 1998;10: 380-384.

8 Schräder R, Esch I, Ensslen R, Fach WA, Merle H, Scherer D, Sievert H, Spiess HF, Zeplin HE: A randomized trial comparing the impact of a nonionic (Iomeprol) versus an ionic (Ioxaglate) low osmolar contrast medium on abrupt vesse closure and ischemic complications after coronary angioplasty. J Am Coll Cardiol 1999;33: 395-402.

9 Robertson HJ: Blood clot formation in angiographic syringes containing nonionic contrast media. Radiology 1987;162:621-622.

10 Chronos NAF, Goodall AH, Wilson DJ, Sigwart U, Buller NP: Profound platelet degranulation is an important side effect of some types of contrast media used in interventional cardiology. Circulation 1993;88:2035-2044.
11 Al Dieri R, De Muinck E, Hemker HC, Beguin $\mathrm{S}$ : An ionic contrast agent inhibits plateletdependent thrombin generation and boosts the effect of abciximab. Thromb Haemost 2001; 85:944-945.

12 Arora R, Khandelwal M, Gopal A: In vivo effects of nonionic and ionic contrast media on beta-thromboglobulin and fibrinopeptide levels. J Am Coll Cardiol 1991;17:1533-1536.

$13 \mathrm{Wu}$ KK, Hoak JC: A new method for the quantitative detection of platelet aggregates in patients with arterial insufficiency. Lancet 1974; ii:924-926.

14 Grotemeyer KH: The platelet reactivity test - a useful 'by-product' of the blood sampling procedure? Thromb Res Suppl 1991;61:423-431.

15 Chaveau J, Fert V, Morel A, Delaage MA: Rapid and specific immunoassay of serotonin. Clin Chem 1991;37:1178-1184.

16 Dawson P, Cousins C, Bradshaw A: The clotting issue: Etiologic factors in thromboembolism. 2. Clinical considerations. Invest Radiol 1993;28(suppl 5):S31-S38.

17 Boneu B, Bes G, Pelzer H, Sié P, Boccalon H: D-Dimers, thrombin antithrombin III complexes and prothrombin fragments 1+2: Diagnostic value in clinically suspected deep vein thrombosis. Thromb Haemost 1991;65:28-31.

18 Sernau T, Wilhelm C, Seyfert U, Gabath S, Henkels M, Amiral J, Bergis KH, Ziegler R, Wahl P, Nawroth PP: Thrombomodulin ist ein Marker für mikrovaskuläre, aber nicht für makrovaskuläre Endothelzell-Schädigung. Vasa 1995;24:347-353.

19 Bach R, Jung F, Scheller B, Özbeck C, Spitzer $\mathrm{S}$, Schieffer H: Factors which influence minor and major complications after diagnostic and therapeutic coronary catheter procedures: Prospective observational study on 7850 patients. Cor Europaeum 1997;6:64-68.

20 Mann KG: Prothrombin and thrombin; in Colman RW, Hirsh J, Marder VJ, Salzman EW (eds): Hemostasis and Thrombosis: Basic Principles and Clinical Practice. Philadelphia, Lippincott, 1994, pp 184-199.

21 Rosenberg RD: The heparin-antithrombin system: A natural anticoagulant mechanism; in Colman RW, Hirsh J, Marder VJ, Salzman EW (eds): Hemostasis and Thrombosis: Basic Principles and Clinical Practice. Philadelphia, Lippincott, 1994, pp 1373-1392.

22 Murakami Y, Ishinaga Y, Sano K, Murakami R, Kinoshita Y, Kitamura J, Kobayashi K, Okada S, Matsubara K, Shimada T, Morioka S: Increased serotonin release across the coronary bed during a nonischemic interval in patients with vasospastic angina. Clin Cardiol 1996;19: 473-476.

23 Vikenes K, Farstad M, Nordrehaug JE: Serotonin is associated with coronary artery disease and cardiac events. Circulation 1999;100:483489.
24 Heptinstall S, White A, Edwards N, Pascoe J, Sanderson HM, Fox SC, Henderson RA: Differential effects of three radiographic contrast media on platelet aggregation and degranulation: Implications for clinical practice? $\mathrm{Br} \mathrm{J}$ Haematol 1998;103:1023-1030.

25 Sakariassen KS, Barstad RM, Hamers MJ, Stormorken $\mathrm{H}$ : Iohexol, platelet activation and thrombosis. 1. Iohexol-induced platelet secretion does not affect thrombus formation in native blood. Acta Radiol 1998;39:349-354.

26 Scheller B, Hennen B, Thünenkötter T, Mrowietz C, Markwirth T, Schieffer H, Jung F: Effect of X-ray contrast media on blood flow properties after coronary angiography. Thromb Res 1999;96:253-260.

27 Bach R, Spitzer R, Janzen I, Jung F, Bonaventura K, Özbek C, Dyckmans J, Schieffer H: Rheological properties of blood after cardiac catheterization with iopromide; in Baert AL, Heuck FHW (eds): Frontiers in European Radiology. Berlin, Springer, 1993, pp 109-119.

28 Levi M, Biemond BJ, Stuck A, Wouter ten Cate $\mathrm{J}$ : The effect of radiological contrast media in animal models of experimental thrombosis. Semin Hematol 1991;28(4 suppl 7):27-41.

29 Aguejouf O, Doutremepuich F, Azougagh OF, Doutremepuich C: Thrombogeneicity of ionic and nonionic contrast media tested in a laser induced rat thrombosis model. Thromb Res 1995; 77:259-269.

30 Corot C, Stucker O, Duverger JP, Pons C, Vicaut E: Effects of iodinated contrast agents on the formation of platelet thrombi in rat arterioles. Invest Radiol 1994;29(suppl 2):S203S205.

31 Meade TW: Hypercoagulability and ischaemic heart disease. Blood Rev 1987;1:2-8.

32 Fuster V, Badimon L, Badimon JJ, Chesebro $\mathrm{JH}$ : The pathogenesis of coronary artery disease and the acute coronary syndromes. Part 1 . N Engl J Med 1992;326:242-250.

33 Harker LA: Role of platelets and thrombosis in mechanisms of acute occlusion and restenosis after angioplasty. Am J Cardiol 1987;60:20B$28 \mathrm{~B}$.

34 Harker LA, Hanson SR, Runge MS: Thrombin hypothesis of thrombus generation and vascular lesion formation. Am J Cardiol 1995;75: 12B-17B.

35 Scheller B, Hennen B, Pohl A, Schieffer H, Markwith T: Acute and subacute stent occlusion. Risk reduction by ionic contrast media. Eur Heart J 2001;22:385-391.

36 Biancardi M, Cimminiello C, Toschi V, Schiavina G, Regalia F, Casolo F, Bonfardeci $\mathrm{G}$ : TAT, F1 + 2, and D-dimer levels in patients after coronary angiography with nonionic or ionic contrast media or after cardiac catheterization. Semin Thromb Hemost 1996;22(suppl 1):61-65.

37 Hoffmann JJML, Tielbeek AV, Krause W: Haemostatic effects of low osmolar non-ionic and ionic contrast media: A double-blind comparative study. Br J Radiol 2000;73:248-255. 